\title{
Twist1-induced epithelial-mesenchymal transition according to microsatellite instability status in colon cancer cells
}

\author{
Bo Young Oh ${ }^{1, *}$, So-Young Kim ${ }^{2, *}$, Yeo Song Lee ${ }^{2}$, Hye Kyung Hong ${ }^{2}$, Tae Won Kim ${ }^{4}$, \\ Seok Hyung Kim ${ }^{3}$, Woo Yong Lee ${ }^{1,4}$, Yong Beom Cho ${ }^{1,4,5}$ \\ ${ }^{1}$ Department of Surgery, Samsung Medical Center, Sungkyunkwan University School of Medicine, Seoul, Korea \\ ${ }^{2}$ Samsung Biomedical Research Institute, Samsung Medical Center, Seoul, Korea \\ ${ }^{3}$ Department of Pathology, Samsung Medical Center, Sungkyunkwan University School of Medicine, Seoul, Korea \\ ${ }^{4}$ Department of Health Sciences and Technology, SAIHST, Sungkyunkwan University, Seoul, Korea \\ ${ }^{5}$ Department of Medical Device Management \& Research, SAIHST, Sungkyunkwan University, Seoul, Korea \\ *These authors have contributed equally to this work \\ Correspondence to: Yong Beom Cho, email: gscyb@skku.edu \\ Woo Yong Lee, email: Iwy555@skku.edu
}

Keywords: Twist1, epithelial to mesenchymal transition, microsatellite instability, colorectal cancer

Received: December 15, $2015 \quad$ Accepted: July 18, 2016

Published: August 01, 2016

\section{ABSTRACT}

Colorectal cancer (CRC) with microsatellite instability (MSI) may exhibit impaired epithelial-mesenchymal transition (EMT), but little is known about the underlying mechanisms of this phenomenon. In this study, we investigated the role of Twist1 and its downstream signaling cascades in EMT induction according to MSI status. To investigate the effects of Twist1 on EMT induction according to MSI status, MSS LS513 and MSI LoVo colon cancer cell lines, which overexpress human Twist1, were generated. Twist1-induced EMT and its downstream signaling pathways were evaluated via in vitro and in vivo experiments. We found that Twist1 induced EMT markers and stem cell-like characteristics via AKT signaling pathways. Twist1 induced activation of AKT and suppression of glycogen synthase kinase (GSK)-3 $\beta$, which resulted in the activation of $\beta$-catenin, increasing CD44 expression. In addition, Twist1 activated the AKT-induced NF-KB pathway, increasing CD44 and CD166 expression. Activation of both the AKT/GSK-3 $\beta / \beta$-catenin and AKT/NF-KB pathways occurred in MSS LS513 cells, while only the AKT/GSK-3 $\beta / \beta$-catenin pathway was activated in MSI LoVo cells. In conclusion, Twist1 induces stem cell-like characteristics in colon cancer cell lines related to EMT via AKT signaling pathways, and those pathways depend on MSI status.

\section{INTRODUCTION}

Epithelial-mesenchymal transition (EMT) is a highly conserved process characterized by the loss of epithelial characteristics and the acquisition of mesenchymal phenotypes [1]. In cancer, tumor cells undergoing EMT gain motility, invasiveness, and stem cell-like characteristics, resulting in cancer progression and metastasis [2-4]. During EMT, tumor cells undergo a loss of epithelial markers, such as E-cadherin, and a gain of mesenchymal markers, such as vimentin and $\mathrm{N}$-cadherin $[1,4,5]$. EMT is induced by transcription factors such as Twist, snail, ZEB, and FOXC [1, 5]. In particular, Twist1 is a key regulator of EMT and a potent promoter of cancer progression and metastasis [6-8], although the underlying mechanisms are poorly understood.

Metastasis is the most common cause of death in colorectal cancer (CRC) patients, which occurs in approximately $50 \%$ of patients during the course of the disease [9-11]. Therefore, many studies have sought to understand the molecular mechanisms of metastasis and have proposed EMT as a candidate mechanism of metastasis in CRC [12-15]. A recent study suggested that EMT is impaired in colon cancer cells with microsatellite instability (MSI) [4]. MSI results from defective DNA mismatch repair, one of the major mechanisms of carcinogenesis $[16,17]$. The MSI phenotype is associated with approximately $10-15 \%$ of sporadic CRC and almost 
all hereditary non-polyposis CRC (HNPCC) [16-18]. Many studies have reported that CRCs with MSI show less frequent metastasis and better prognosis compared to microsatellite stable (MSS) CRC [18, 19]. However, little is known about the molecular pathogenesis of prognostic differences between MSI and MSS CRC. Thus, investigating the morphological and functional differences of Twist1-induced EMT pathways in MSS and MSI CRC may help elucidate the molecular mechanisms of metastasis in CRC. In this study, we investigated the role of Twist1 and its downstream signaling cascades for inducing EMT in MSS and MSI colon cancer cell lines.

\section{RESULTS}

\section{Induction of EMT by Twist1 in MSS and MSI colon cancer cell lines}

To investigate the effect of Twist1 on EMT induction according to MSI status, MSS LS513 and MSI LoVo cells overexpressing human Twist1 were generated via lentivirus transduction. EMT induction appeared in these cells with morphological changes such as loss of cell polarity, spindle-like cell shape, and loss of cell-to-cell adhesion. In contrast, epithelial features still remained in control green fluorescent protein (GFP)expressing cells (Figure 1A). We carried out western blotting to identify EMT markers depending on Twist1 overexpression. Twist1 overexpression induced loss of the epithelial marker E-cadherin, which is involved in the early stages of EMT, and then loss of the E-cadherin promoted $\beta$-catenin release in both MSS LS513 and MSI LoVo cells. However, upregulation of mesenchymal marker vimentin was prominent only in MSS LS513 cells (Figure 1B). Similar results were noted by real-time PCR (Figure 1C).

In addition, to investigate the effect of Twist1 on cancer progression according to MSI status, we evaluated cell migration and cell invasion in MSS LS513 and MSI LoVo cells. Twist1-overexpressing cells had more mobile and invasive properties than control GFP-expressing cells, and these functional changes were more prominent in MSS LS513 than in MSI LoVo cells (Figures 1D and 1E).
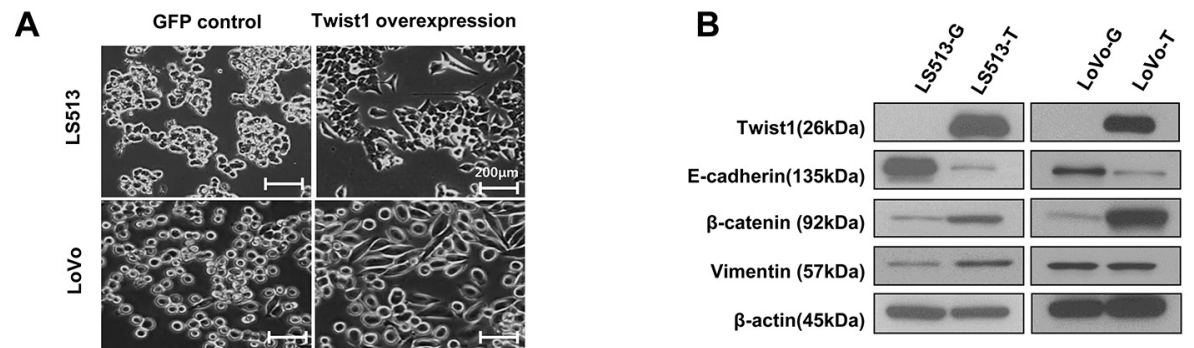

C
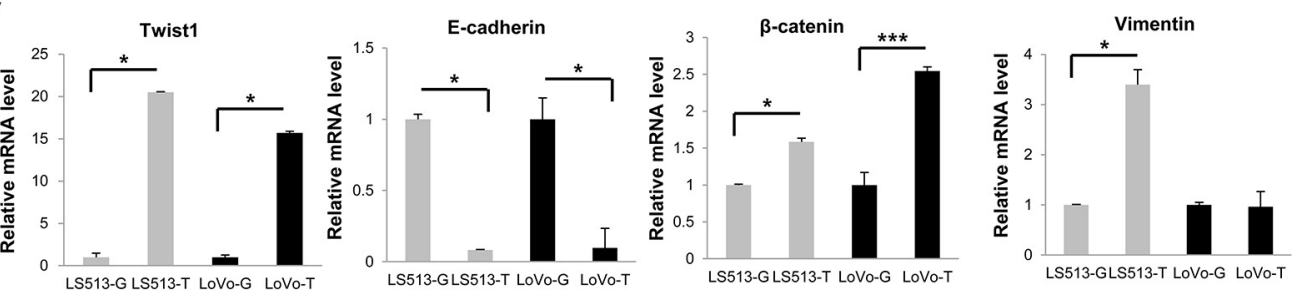

D
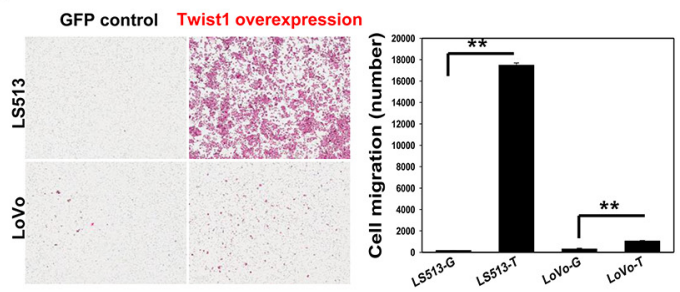

E

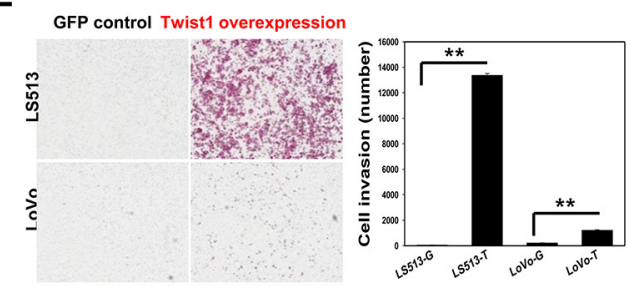

Figure 1: Twist1 induced EMT in MSS LS513 and MSI LoVo colon cancer cell lines. EMT induction was more prominent in MSS LS513 compared to MSI LoVo cells. A. Cellular morphologic changes depending on Twist1 overexpression are shown at 40x magnification. Scale bar: $200 \mu \mathrm{m}$. B. Expression of E-cadherin, $\beta$-catenin, and vimentin depending on Twist 1 overexpression was analyzed by western blot. $\beta$-actin was used as a loading control. C. Transcriptional levels of E-cadherin, $\beta$-catenin, and vimentin depending on Twistl overexpression were analyzed by real-time PCR. D. Cell migration depending on Twist1 overexpression was assessed by transwell migration chamber assay. E. Cell invasiveness depending on Twist1 overexpression was assessed by transwell migration chamber assay. Columns $=$ mean $\pm \operatorname{SD}(\mathrm{n}=3){ }^{*} \mathrm{p}<0.05, * * \mathrm{p}<0.01, * * * \mathrm{p}<0.001$. 


\section{Activation of AKT signaling pathway by Twist1 in MSS and MSI colon cancer cell lines}

Twist1 has been shown to activate AKT expression and its downstream signaling pathway [20]. To investigate the effect of Twist1 on activation of the AKT downstream signaling pathway according to the MSI status, we evaluated the phosphorylation of AKT (Ser473) in MSS LS513 and MSI LoVo cells. In addition, expression of the glycogen synthase kinase (GSK)-3 $\beta$ (Tyr216) inactive form, which is a downstream target of AKT, and $\beta$-catenin were evaluated. We found that Twist1 induced activation of AKT and suppression of GSK-3 $\beta$ (which resulted in nuclear translocation of $\beta$-catenin) in MSS LS513 cells (Figures 2A and 2C). In addition, in MSS LS513 cells overexpressing Twist1, AKT activated inhibitor of $\kappa \mathrm{B}$ kinase (IKK), which activated the nuclear factor kappalight-chain-enhancer of activated B cells (NF- $\mathrm{KB}$ ) via phosphorylation of total inhibitor of $\kappa \mathrm{B}$ (I $\kappa \mathrm{B}$ ) binding on NF- $\mathrm{NB}$, thereby allowing active NF- $\mathrm{\kappa B}$ to translocate into the nucleus (Figures 2B and 2C). However, similar findings were not observed in MSI LoVo cells. In LoVo cells, Twist1 activated AKT and suppressed GSK-3 $\beta$, which then led to nuclear translocation of $\beta$-catenin; however, it did not activate NF- $\mathrm{kB}$ via the phosphorylation of IкB (Figures 2A-2C).

Furthermore, we investigated whether inhibition of NF- $\kappa B$ signaling suppressed invasive properties of Twist1overexpressing cells. NF- $\mathrm{kB}$-activating LS513 cells were treated with $2 \mu \mathrm{M}$ quinacrine, an NF- $\kappa B$ inhibitor, for 24 hours, and cell invasion assay was then performed. Quinacrine treatment led to a significant decrease in cell invasiveness in Twist1-overexpressing LS513 cells (Figure 2D). These findings suggest that Twist1 facilitates AKT-induced NF- $\mathrm{KB}$ pathway, increasing cancer cell invasiveness.

\section{Induction of stem cell-like characteristics by Twist1 in MSS and MSI colon cancer cell lines}

To examine Twist1-induced stem cell-like characteristics, we investigated the ability of cells to self-
A

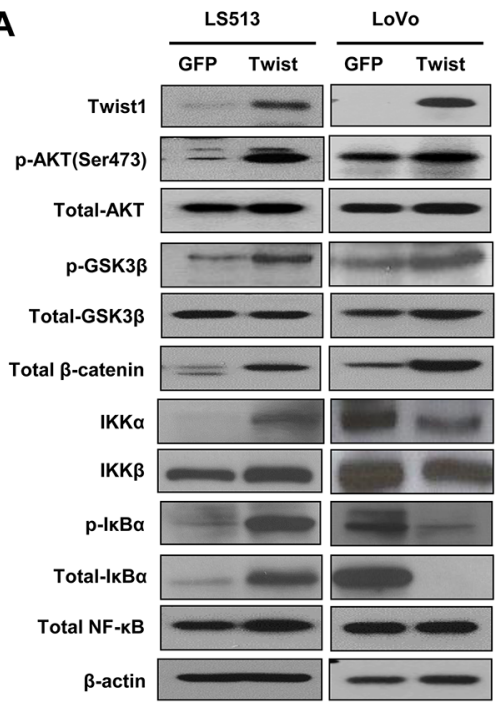

C

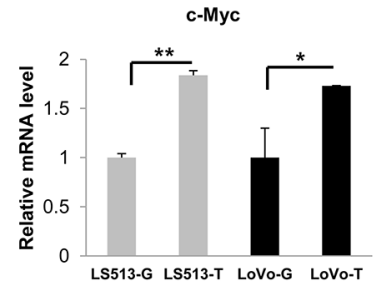

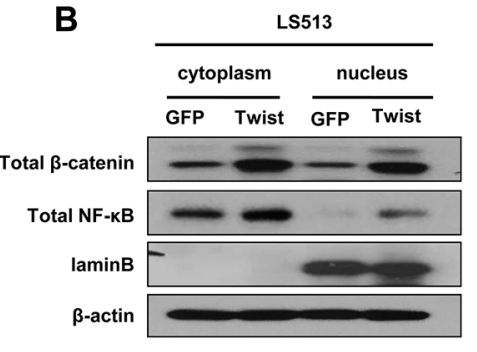

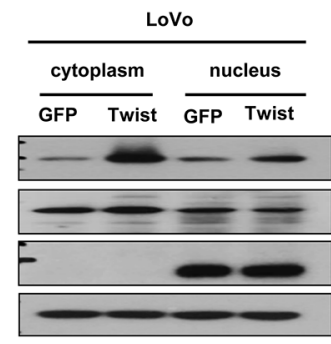

LoVo
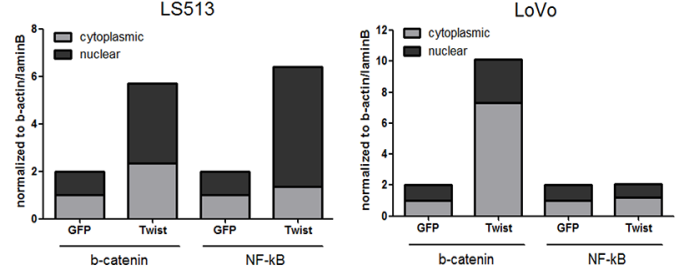

D
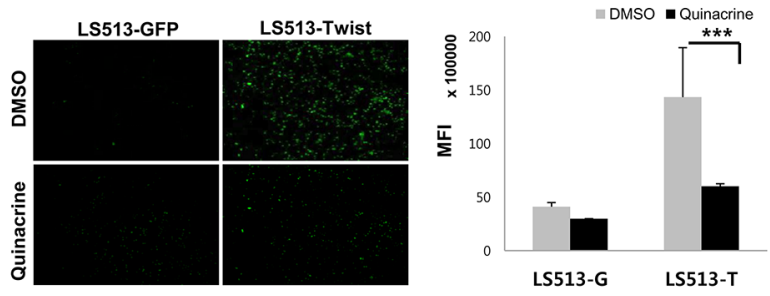

Figure 2: Twist1 activated the AKT signaling pathway in MSS LS513 and MSI LoVo colon cancer cell lines. The AKT/GSK-3 $\beta / \beta$-catenin pathway was activated in MSS LS513 and MSI LoVo cells, and the AKT/NF-kB pathway was activated in MSS LS513 cells. A. Expression of molecules involved in the AKT/GSK-3 $3 / \beta$-catenin pathway and AKT/NF-kB pathway depending on Twist1 overexpression was analyzed by Western blot. B. Subcellular localization of $\beta$-catenin and NF- $\kappa B$ depending on Twistl overexpression was analyzed in each cell line. C. Transcriptional levels of c-Myc, a target of $\beta$-catenin, depending on Twist1 overexpression were analyzed via real-time PCR. D. Inhibition of NF-kB by quinacrine suppressed invasiveness of Twist1-overexpressing MSS LS513 cells. Representative images of invading cells are shown (upper panel), and the mean fluorescence intensities (MFIs) of invaded areas under the various conditions are presented in bar graphs (lower panel). Columns $=$ mean $\pm \operatorname{SD}(\mathrm{n}=3) .{ }^{*} \mathrm{p}<0.05, * * \mathrm{p}<0.01,{ }^{* * *} \mathrm{p}<0.001$ 
renew by evaluating colony formation. Twist1 enhanced colony formation in MSS LS513 cells, but this finding was not marked in MSI LoVo cells (Figure 3).

To further confirm these findings, we also evaluated the expression of stem cell markers, such as CD44 and CD166, by using fluorescence-activated cell sorting (FACS), immunofluorescence staining, real-time PCR, and immunoblotting. As shown in FACS, Twistl elevated the level of CD44 and CD166 expression in MSS LS513 cells. However, in MSI LoVo cells, Twist1 promoted the expression of CD44, but not CD166 (Figure 4A). Immunofluorescence staining, real-time PCR, and immunoblotting confirmed that expression of both CD44 and CD166 was increased in Twist1-overexpressing MSS LS513 cells, but only CD44 expression was increased in Twist-overexpressing MSI LoVo cells (Figures 4B-4D).

In addition, we investigated whether expression of CD44 and CD166 was associated with cancer cell invasiveness. Neutralizing antibodies against human CD44 and CD166 were added to Twist1-overexpressing cells and a cell invasion assay was then performed. Neutralizing antibodies against CD44 and CD166 inhibited the invasiveness of cancer cells in MSS LS513 cells. However, these inhibiting effects were not marked in MSI LoVo cells (Figure 5).

\section{Twist1-induced tumorigenesis in xenografts with MSS and MSI colon cancer}

To investigate Twist1-induced tumorigenesis in vivo according to MSI status, we generated xenografts by implanting MSS LS513 and MSI LoVo colon cancer cells. Consistent with in vitro findings, Twist1-overexpressing MSS LS513 tumors displayed more prominent tumorigenesis compared to GFP-expressing tumors. Between one and three weeks, mean tumor volume increased from 100 to $650 \mathrm{~mm}^{3}$ in Twist1-overexpressing LS513 tumors and from 100 to $200 \mathrm{~mm}^{3}$ in control LS513 tumors $(P=0.003)$. Tumors grew rapidly after the initial period passed, suggesting that Twist1 affects the late period of tumor development in MSS LS513 tumors (Figure 6). In contrast, as shown in Figure 6, Twist1 did not induce tumorigenesis in MSI LoVo tumors. This outcome was consistent with in vitro findings that activation of the Twist1-induced AKT/NF- $\kappa$ B pathway promoting invasion and tumorigenesis was not observed in MSI LoVo cells.

\section{DISCUSSION}

In this study, we examined whether Twist1 induced stem cell-like characteristics by EMT via AKT signaling pathways in colon cancer cell lines and if those pathways depended on MSI status. First, Twist1 activated AKTinduced NF- $\kappa$ B pathway, increasing CD44 and CD166 expression. Second, Twist1 induced activation of AKT and suppression of GSK-3 $\beta$, which resulted in activation of $\beta$-catenin, thereby increasing CD44 expression. The AKT/ $\mathrm{NF}-\kappa \mathrm{B}$ pathway and AKT/GSK-3 $\beta / \beta$-catenin pathway activated in the MSS LS513 cells, while only the AKT/ GSK- $3 \beta / \beta$-catenin pathway activated in the MSI LoVo cells in response to Twist1 overexpression (Figure 7).

Twist1, the basic helix-loop-helix transcription factor, is a potent promoter of cancer progression and metastasis [21]. It is a key regulator of EMT and promotes cancer cells to display mesenchymal phenotypes such as a spindle-like shape, proliferation, migration, and invasion $[6,7,21-23]$. Several studies have suggested that Twist 1 is associated with pathways in the EMT process such as Wnt/ $\beta$-catenin signaling [24], PI3K/AKT/TGF- $\beta$ signaling $[25,26]$, AKT2 signaling [20], and NF- $\kappa$ B signaling[21] in breast cancer cells. However, the mechanisms by which
A

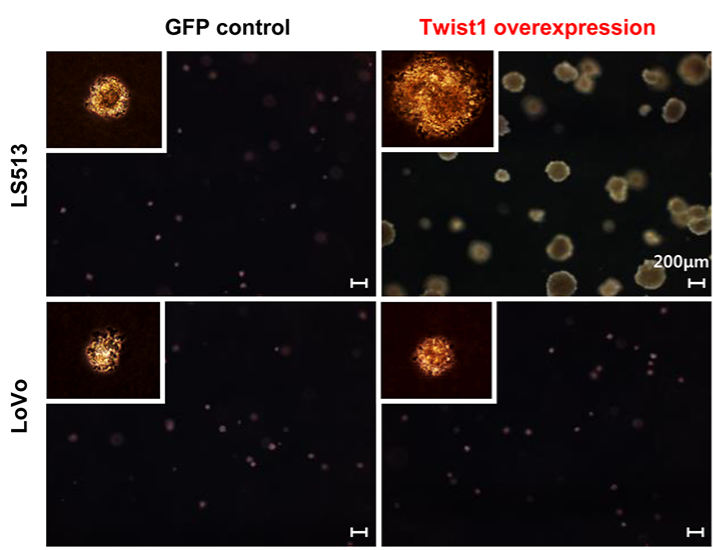

B

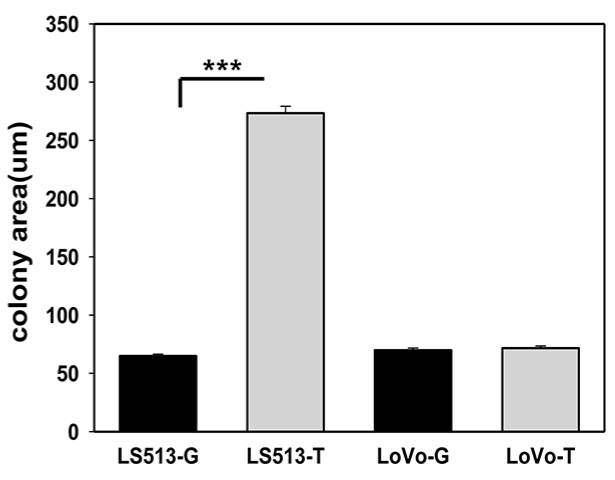

Figure 3: Twist1 enhanced colony formation in MSS LS513 cells compared to in MSS LoVo cells. A. The ability of cells to self-renew was assessed via colony formation. The white rectangle in the spherical formation image denotes a region shown at 20x magnification. Scale bar: $200 \mu \mathrm{m}$. B. Cell growth was quantified based on the number and size of colonies. Columns $=\operatorname{mean} \pm \mathrm{SD}(\mathrm{n}=3)$. $* \mathrm{p}<0.05, * * \mathrm{p}<0.01, * * * \mathrm{p}<0.001$. 
A

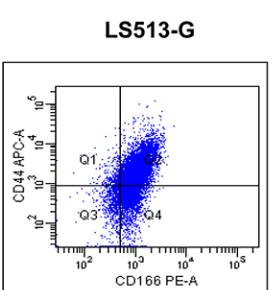

LoVo-G

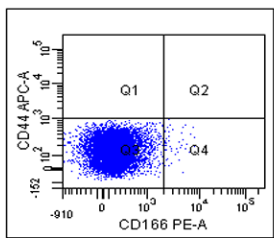

LS513-T

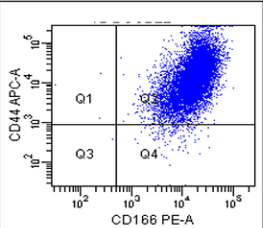

LoVo-T

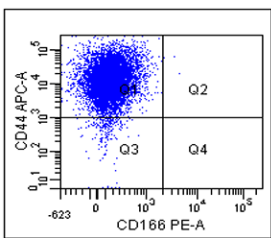

B

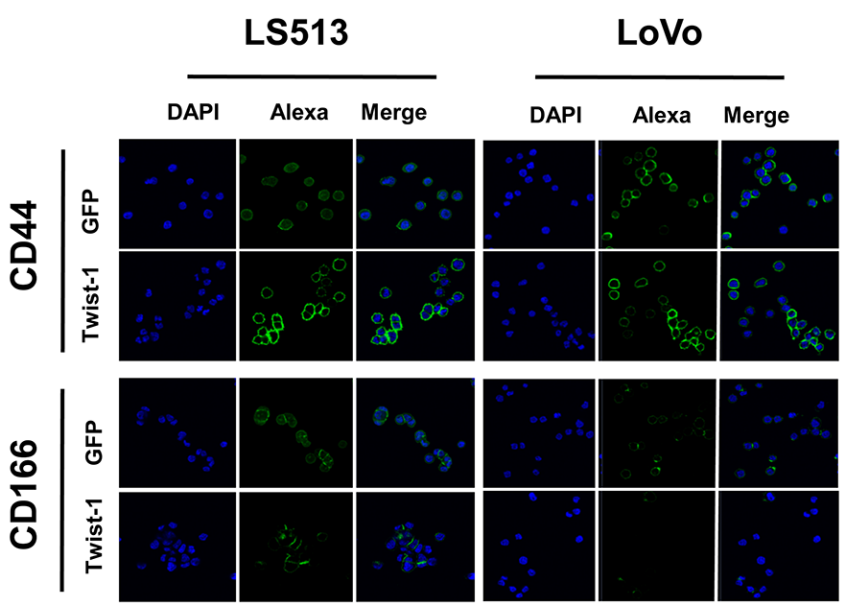

C
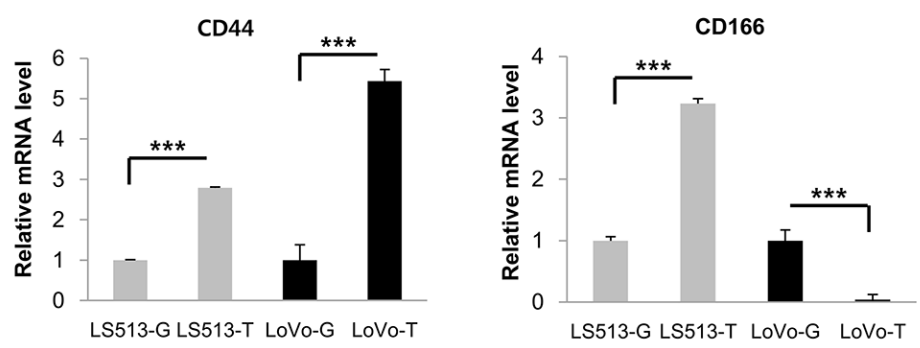

D

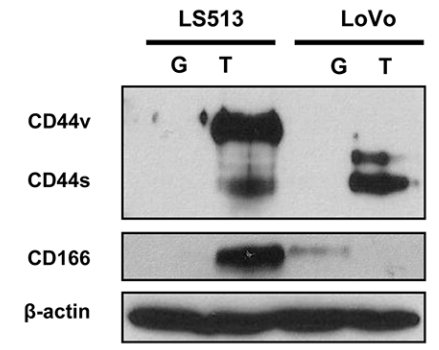

Figure 4: Twist1 elevated the level of cancer stem cell markers in MSS LS513 and MSI LoVo colon cancer cell lines. Expression of CD44 was higher in MSS LS513 and MSI LoVo cells, and expression of CD166 was higher in MSS LS513 cells. A. Expression of CD44 and CD166 depending on Twist1 overexpression was analyzed by FACS. B. Expression of CD44 and CD166 depending on Twist1 overexpression was analyzed by immunofluorescent staining; original magnification, 400x. C. Transcriptional levels of CD44 and CD166 depending on Twist1 overexpression were analyzed by real-time PCR. D. Expression of CD44 variant isoforms (CD44v), CD44 standard isoforms $(\mathrm{CD} 44 \mathrm{~s})$, and CD166 depending on Twist1 overexpression was analyzed via immunoblot. Columns $=$ mean $\pm \mathrm{SD}(\mathrm{n}=3)$. $* \mathrm{p}<0.05, * * \mathrm{p}<0.01, * * \mathrm{p}<0.001$.

A

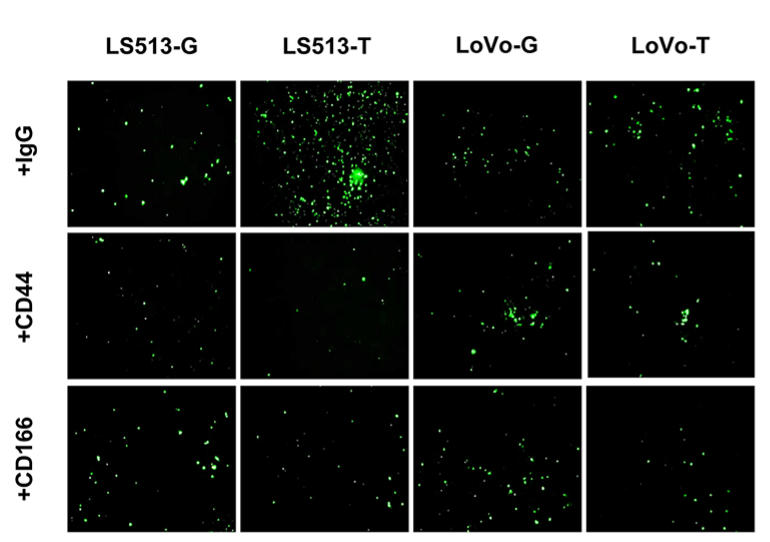

B
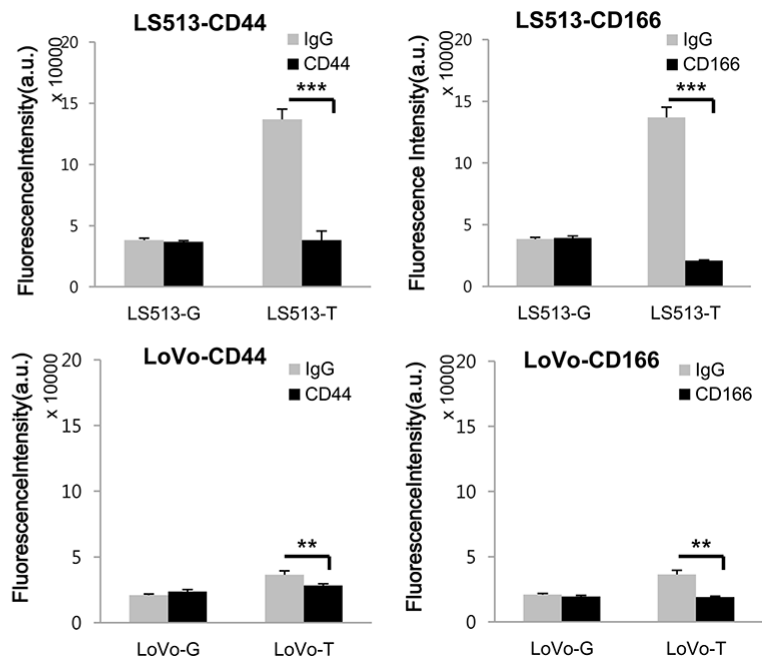

Figure 5: Invasion assay was performed by adding neutralizing antibodies against CD44 and CD166 in MSS LS513 and MSI LoVo colon cancer cell lines. The inhibiting effects of neutralizing antibodies were marked in MSS LS513 cells, but were minimal in MSI LoVo cells. A. Representative images of invading cells are shown. B. The mean fluorescence intensities (MFIs) of invaded areas under the various conditions are presented. Columns $=$ mean $\pm \mathrm{SD}(\mathrm{n}=3) .{ }^{*} \mathrm{p}<0.05,{ }^{* *} \mathrm{p}<0.01,{ }^{* * *} \mathrm{p}<0.001$. 


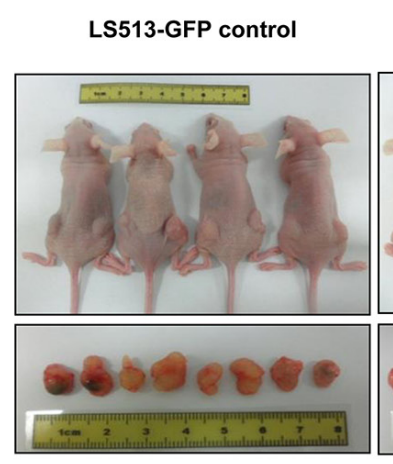

LoVo-GFP control

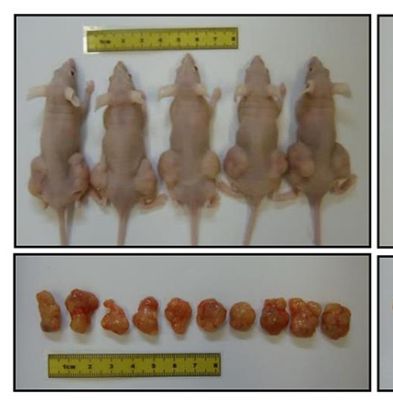

LS513-Twist

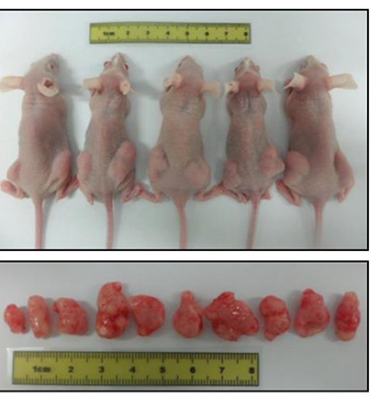

LoVo-Twist

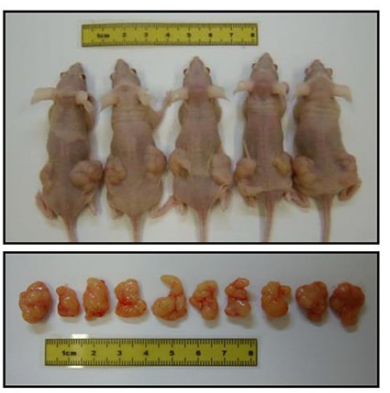

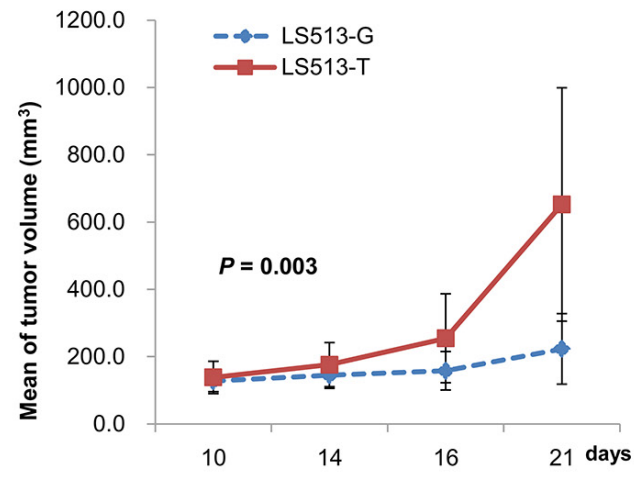

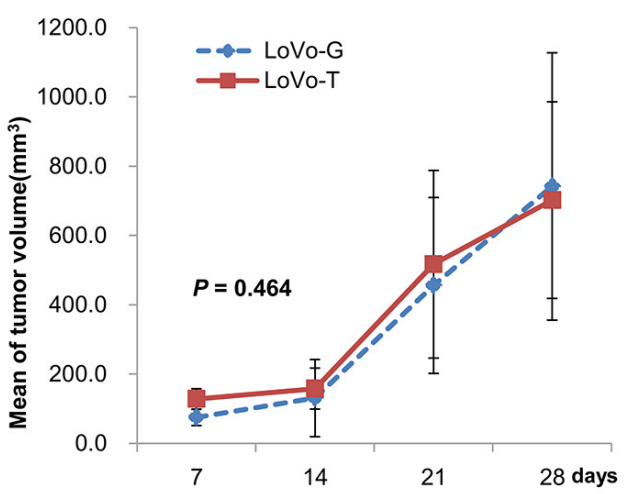

Figure 6: Twist1-induced tumorigenesis in xenografts varied according to MSI status. Tumorigenesis was more prominent in Twist1-overexpressing MSS LS513 tumors compared to GFP-expressing tumors. In contrast, tumorigenesis was not increased in Twist1overexpressing LoVo cells compared to GFP-expressing LoVo cells. Injected cell counts $=5$ x 106/100 $\mu 1$.

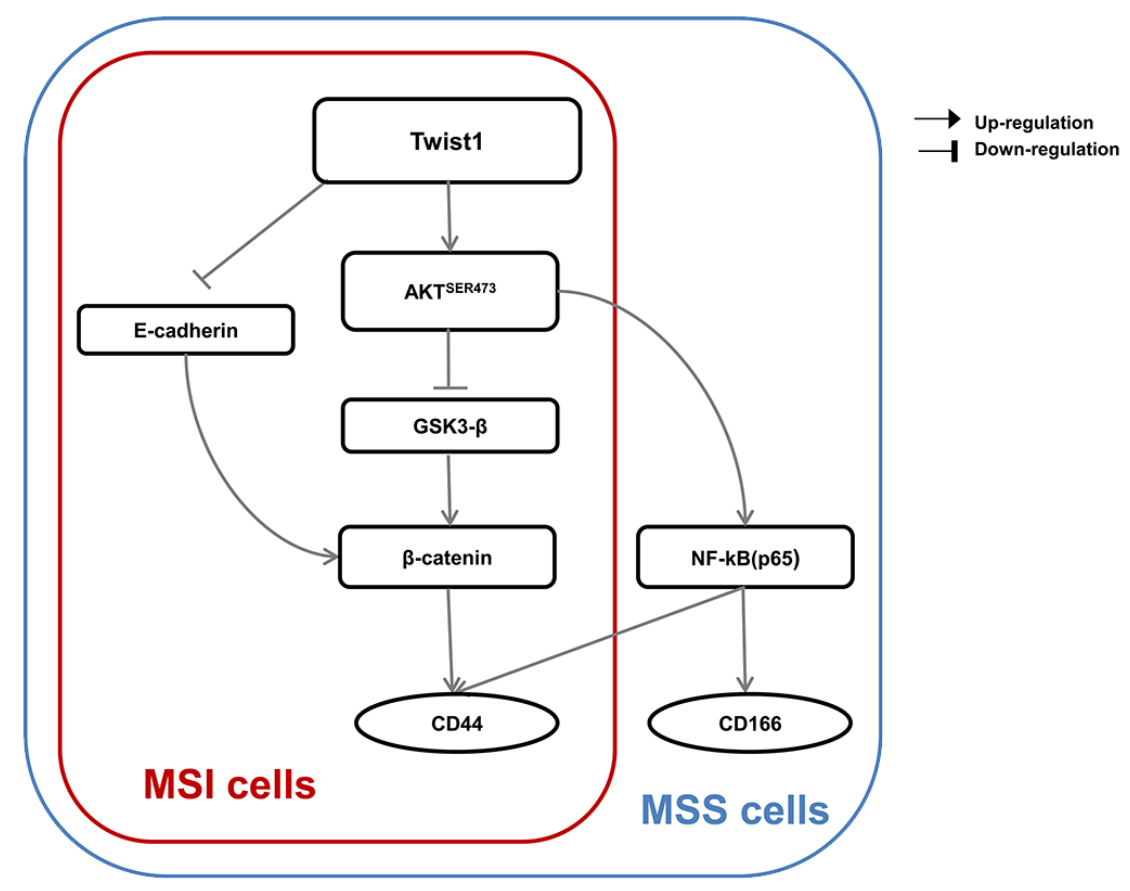

Figure 7: A proposed model for a Twist1-induced EMT signaling pathway according to MSI status is presented. In

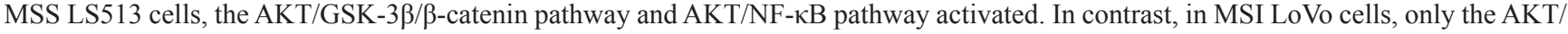
GSK-3 $\beta / \beta$-catenin pathway activated. 
Twist1 promotes EMT are still poorly understood. Many studies have shown that cancer cells can have stem celllike characteristics during EMT, which results in colony formation and expression of stem cell markers [27-30]. CSCs known as tumor-initiating cells have been identified in several tumors [31-33]. These cells have characteristics such as self-renewal, tumor formation, and resistance to therapy, so they lead to cancer recurrence and metastasis [30, 34, 35].

MSI results from defective DNA mismatch repair, which is one of the major mechanisms of carcinogenesis $[16,17]$. MSS CRC patients experience more frequent metastasis and worse prognosis compared to MSI CRC patients $[18,19]$. In a study of 2,141 CRC patients, distant metastases were more frequent in MSS patients than in MSI patients $(22 \%$ vs. 12\%) [36]. Many studies have identified these prognostic differences between MSS and MSI CRC patients, but little is known about the underlying mechanisms. Recent studies have suggested that EMT is impaired in colon cancer with MSI compared to that with MSS [4, 37, 38]. However, a signaling pathway according to MSI status was not identified.

We hypothesized that differences in EMT signaling pathways might be one of the mechanisms that cause prognostic differences according to the MSI status. In our study, Twist1 effectively induced the EMT process in MSS LS513 cells. In contrast, Twist1 induced only a partial EMT process in MSI LoVo cells, and the following phenomena occurred. First, the epithelial marker E-cadherin was downregulated, but the mesenchymal marker vimentin was not upregulated. Second, cell mobility and invasiveness were not effectively increased. Third, the AKT/GSK-3 $\beta / \beta$-catenin pathway was activated, but not the AKT/NF- $\mathrm{B}$ pathway. Finally, expression of CD44 increased, not CD166. These results provide experimental evidence for the establishment of therapeutic strategies targeting EMT pathways according to MSI status.

There were some limitations to our study. We used one cell line each with an MSS and MSI phenotype, respectively. In addition, we did not describe the reason why the $\mathrm{AKT} / \mathrm{NF}-\kappa \mathrm{B}$ pathway did not activate in the MSI cell line. However, this study is the first focusing on the EMT signaling cascade according to MSI status. In addition, we confirmed in vitro results with additional xenograft experiments, suggesting the possibility of applying these results to human cancers. Cancer cells with stem cell-like characteristics are induced by EMT and have therapeutic resistance. These cells can repopulate primary tumors, resulting in cancer recurrence and metastasis. Thus, selective targeting of these cells is needed. Our results suggest that targeting the AKT/NF$\kappa \mathrm{B}$ and $\mathrm{AKT} / \mathrm{GSK}-3 \beta / \beta$-catenin pathways can suppress the stem cell-like characteristics associated with Twist1induced EMT. Furthermore, these pathways are different according to MSI status, so a different approach is needed for these two groups. Of note, inhibition of the EMT pathway effectively suppressed cell invasiveness in the MSS phenotype corresponding to the majority of CRC cases, which can help improve survival in CRC patients.

In conclusion, Twist1 induces stem cell-like characteristics by EMT via AKT signaling pathways in colon cancer cell lines, and these pathways depend on the MSI status. This study may be useful for developing new therapeutic strategies according to MSI status and may help to improve survival outcome in CRC patients.

\section{MATERIALS AND METHODS}

\section{Cell cultures and viral transduction}

MSS LS513 and MSI LoVo colon cancer cell lines were cultured in an RPMI 1640 medium (Gibco, Grand Island, NY, USA) supplemented with $10 \%$ fetal bovine serum (FBS; Gibco), and 1\% penicillin-streptomycin (Gibco) in a $5 \% \mathrm{CO}_{2}$ incubator at $37^{\circ} \mathrm{C}$. The medium was replaced every 2 days. Lentiviruses expressing human Twist 1 and GFP were provided by Dr. Seok-Hyung Kim (Department of Pathology, Samsung Medical Center) [39]. For lentiviral transduction of LS513 and LoVo cells, 100 multiplicity of infection Twist1 or GFP lentiviruses were added to a well containing $5 \times 10^{4}$ cells, medium and $8 \mu \mathrm{g} /$ $\mathrm{ml}$ polybrene. After 24 hours of incubation, transduced cells were selected with $1,000 \mu \mathrm{g} / \mathrm{ml}$ hygromycin (Sigma, St. Louis, MO, USA). GFP lentivirus was used as a control. Selected cells were maintained in growth medium with $500 \mu \mathrm{g} / \mathrm{ml}$ hygromycin in a $5 \% \mathrm{CO}_{2}$ incubator at $37^{\circ} \mathrm{C}$.

\section{Western blot}

To prepare whole-cell extracts, cells were lysed using a protein lysis buffer (Pro-prep, Intron) including a protease inhibitor. Then, $40-60 \mu \mathrm{g}$ of protein extract were incubated with primary antibodies against Twist1 (ab50887, Abcam), E-cadherin (catalog \# 610181, BD), vimentin (sc-32322, Santa Cruz), total $\beta$-catenin (catalog \# 610154, BD), phospho- $\beta$-catenin (CST-9561, Cell Signaling), total AKT (CST-4691, Cell Signaling), phospho-AKT (CST-4060, Cell Signaling), total phospho-GSK3 (CST-9315, Cell Signaling), phosphoGSK3 (04-1075, Millipore), IKK $\alpha$ (CST-2682, Cell Signaling), IKK $\beta$ (CST-2370, Cell Signaling), I $\mathrm{B} \alpha$ (sc-371,Santa Cruz), phospho-IкB $\alpha$ (CST-2859, Cell Signaling), p65 (sc-8008, Santa Cruz), and CD44 (CST3570, Cell Signaling), followed by incubation with goat anti-mouse IgG or goat anti-rabbit IgG secondary antibodies conjugated to horseradish peroxidase (SantaCruz). Fractionation was performed using NE-PER Nuclear and Cytoplasmic Extraction Reagents (\#78833, Thermo Fisher, San Jose, CA) via sequential extraction of cytosolic and nuclear proteins in non-ionic detergent 
for investigation of $\mathrm{b}$-catenin and NF-kB localization. Cells were lysed with cytoplasmic lysis buffer for $15 \mathrm{~min}$ on ice then spun for 5 min to collect cytosolic lysate. Pellets were washed with cytoplasmic lysis buffer, and then lysed with nuclear lysis buffer for $40 \mathrm{~min}$ on ice. The lysates were spun for $10 \mathrm{~min}$ at $12,000 \mathrm{xg}$ at $4^{\circ} \mathrm{C}$ to collect nuclear lysates. $\beta$-actin (CST-3700, Cell Signaling) and laminB (Sc-6216, Santa Cruz) were used as cytosolic/total and nuclear normalized protein controls, respectively, in Western blotting.

\section{Quantitative real-time PCR}

Total RNA was extracted from Twist1-transfected or untransfected cells (RNAprep Mini kit, Qiagen), and 500 ng RNA was subjected to reverse transcription using MuLV reverse transcriptase (NEB). Real-time quantitative PCR amplification was performed with a two-step TaqMan Probe Master Mix (Roche, Germany) in a real-time system (ABI, USA). Human-specific TaqMan PCR primers and probes (Roche, Germany) were used to analyze expression of the following genes: Twist 1, E-cadherin, $\beta$-catenin, vimentin, AKT, GSK-3 $\beta$, $I \kappa B \alpha, p 65, C D 44, C D 166$, and $\beta$-actin (Supplement Table $\mathrm{S} 1)$. mRNA levels of specific genes were calculated as $\Delta \Delta \mathrm{Ct}$ and normalized to $\beta$-actin.

\section{Cell migration and invasion assays}

Cell migration assays were carried out using uncoated Matrigel transwell migration chambers (BD Bioscience, CA) in 24-well cell culture plates. In contrast, cell invasion assays were carried out using a Matrigel invasion chamber (BD Bioscience, CA) hydrated for at least 2 hour with $500 \mu$ l serum-free RPMI in the bottom of the well and $500 \mu$ in the top of the chamber. After hydration of the Matrigel, DMEM in the bottom of the well was replaced with $700 \mu \mathrm{l}$ of RPMI containing $10 \%$ FBS. Stable cells $\left(5 \times 10^{4} /\right.$ well) were loaded in migration and invasion chambers with $500 \mu \mathrm{l}$ of serum-free RPMI medium. In the lower chambers, $700 \mu$ of RPMI supplemented with $10 \%$ FBS was added as a chemo-attractant. Plates were incubated for 24 or 48 hours and then stained with calcein $(2 \mu \mathrm{M}$, BD Biosciences, CA). Cell migration and invasion were quantified using fluorescence with a VICTOR2 Multilabel Counter (Perkin Elmer) equipped with a $485 / 520 \mathrm{~nm}$ filter set.

\section{Soft agar colony formation assay}

A colony-forming mixture containing 1.2\% agar solution, $2 \times$ DMEM medium without serum, and 1,500 $\mu \mathrm{l}$ of stable cell $\left(2 \times 10^{4} /\right.$ well) suspension $(1: 1: 1)$ was added to 24-well plates, and plates were incubated for 8-10 days. Colonies were photographed with an inverted microscope
(Olympus, USA), and cell growth was quantified based on the number and size of the colonies.

\section{FACS}

Cells were suspended in phosphate buffered saline (PBS) and incubated with an FcR blocking reagent (Miltenyi Biotec, Germany) for 10 minutes. Then, cells were stained with the directly conjugated monoclonal antibodies anti-human CD166-PE, CD44-APC, antihuman IgG-PE isotype, and anti-human IgG-APC isotype (Miltenyi Biotec, Germany) for 30-40 minutes at $4{ }^{\circ} \mathrm{C}$. The IgG isotype control was incubated in parallel. Flow cytometry was performed with an Accuri C6 (BD Biosciences, CA) using the CFlow software (BD Biosciences, CA).

\section{Immunofluorescent staining}

Sterile cover slips were placed in 12- or 24-well plates and then rinsed with PBS, followed by a quick rinse with culture medium. Cells were plated on the cover slips at a density of approximately $10,000 / \mathrm{cm}^{2}$ and then fixed in a freshly prepared solution of $4 \%$ formaldehyde in PBS and quenched with $50 \mathrm{mM} \mathrm{NH}_{4} \mathrm{Cl}$ for 15 minutes. Cells were blocked and permeabilized (if the first antibody was against a cytoplasmic domain of the protein or was present intracellularly) for one hour at room temperature. Next, the cells were incubated with the directly conjugated monoclonal antibodies anti-human CD166-PE, CD44-APC, and anti-mouse IgG isotype in a blocking/permeabilization solution overnight at $4{ }^{\circ} \mathrm{C}$. After incubation, the cover slips were rinsed with distilled water and incubated with the secondary antibody Alexa488 (Miltenyi Biotec, Germany) to rule out nonspecific binding and cross-reaction between the secondary antibodies. The negative control was incubated with mouse $\operatorname{IgG}$ instead of the first antibody, followed by incubation with a secondary antibody to check for nonspecific binding. Images of immunofluorescence were analyzed with a confocal LSM700 microscope (Zeiss, Germany).

\section{Antibody neutralization}

Stable cells were pre-incubated in a serum-free medium containing an RPMI-supplemented neutralization antibody against CD44 or CD166 (1:10 dilution, Mitenyi Bitotec) for one hour. These cells $\left(5 \times 10^{4} /\right.$ well $)$ were used in an in vitro invasion assay using BioCoat Matrigel invasion chambers (BD, Biosciences, CA). IgG was used as a control for antibody neutralization. After that, a cell invasion assay was performed by staining with calcein; fluorescence was quantified with a VICTOR2 Multilabel Counter (Perkin Elmer) equipped with a 485/520 nm filter [40]. 


\section{Xenograft experiments}

We examined tumorigenesis in vivo, using an assay to evaluate cancer growth induced by Twist 1 overexpression. Cells ( $\left.5 \times 10^{6} / 100 \mu \mathrm{l}\right)$ overexpressing Twist 1 were suspended in $50 \mu \mathrm{l}$ of PBS supplemented with $50 \%$ Matrigel and injected subcutaneously into the flanks of 6-week-old female BALB/c nu/nu mice (Charles River Laboratories, Wilmington, USA). Tumor size was measured once a week with a caliper, and tumor volume was calculated using the following formula: short length ${ }^{2} \mathrm{x}$ long length/2. Mice were sacrificed 3-4 weeks after inoculation or as soon as a reduction in vitality was observed. Animal experiments were reviewed and approved by the Institutional Animal Care and Use Committee (IACUC) of the Samsung Biomedical Research Institute (SBRI) (\#20150122002). SBRI is an Association for Assessment and Accreditation of Laboratory Animal Care International (AAALAC International)-accredited facility and abides by the Institute of Laboratory Animal Resources (ILAR) Guide.

\section{Statistical analysis}

All data are presented as the mean \pm standard deviation. Student's $t$ tests comparing data from each experiment were performed using the SigmaPlot version 10 software (Systat Software Inc.). All experiments were done at least three times. $P$-values less than 0.05 were considered statistically significant.

\section{ACKNOWLEDGMENTS}

This study was supported by the Ministry of Science, ICT, \& Future Planning (NRF-2012R1A1A2043666), a grant from the Korea Health Technology R\&D project through the Korea Health Industry Development Institute (KHIDI), funded by the Ministry of the Health \& Welfare, Republic of Korea (HI14C3418), and a Samsung Biomedical Research Institute grant (CB11231).

\section{CONFLICTS OF INTEREST}

None declared.

\section{FUNDING}

The funding source did not have any role in the design of the study, in the analysis of the data, or in the writing of the paper.

\section{REFERENCES}

1. Kim A, Bae YK, Gu MJ, Kim JY, Jang KY, Bae HI, Lee HJ and Hong SM. Epithelial-mesenchymal transition phenotype is associated with patient survival in small intestinal adenocarcinoma. Pathology. 2013; 45:567-573.
2. Thiery JP. Epithelial-mesenchymal transitions in tumour progression. Nat Rev Cancer. 2002; 2:442-454.

3. Thiery JP and Sleeman JP. Complex networks orchestrate epithelial-mesenchymal transitions. Nat Rev Mol Cell Biol. 2006; 7:131-142.

4. Pino MS, Kikuchi H, Zeng M, Herraiz MT, Sperduti I, Berger D, Park DY, Iafrate AJ, Zukerberg LR and Chung DC. Epithelial to mesenchymal transition is impaired in colon cancer cells with microsatellite instability. Gastroenterology. 2010; 138:1406-1417.

5. Celesti G, Di Caro G, Bianchi P, Grizzi F, Basso G, Marchesi F, Doni A, Marra G, Roncalli M, Mantovani A, Malesci A and Laghi L. Presence of Twist1-positive neoplastic cells in the stroma of chromosome-unstable colorectal tumors. Gastroenterology. 2013; 145:647-657 e615.

6. Yang J, Mani SA, Donaher JL, Ramaswamy S, Itzykson RA, Come C, Savagner P, Gitelman I, Richardson A and Weinberg RA. Twist, a master regulator of morphogenesis, plays an essential role in tumor metastasis. Cell. 2004; 117:927-939.

7. Matsuo N, Shiraha H, Fujikawa T, Takaoka N, Ueda N, Tanaka S, Nishina S, Nakanishi Y, Uemura M, Takaki A, Nakamura S, Kobayashi Y, Nouso K, Yagi T and Yamamoto $\mathrm{K}$. Twist expression promotes migration and invasion in hepatocellular carcinoma. BMC Cancer. 2009; 9:240.

8. Ru GQ, Wang HJ, Xu WJ and Zhao ZS. Upregulation of Twist in gastric carcinoma associated with tumor invasion and poor prognosis. Pathol Oncol Res. 2011; 17:341-347.

9. Jemal A, Bray F, Center MM, Ferlay J, Ward E and Forman D. Global cancer statistics. CA Cancer J Clin. 2011; 61:69-90.

10. Oh BY, Kim KH, Chung SS, Hong KS and Lee RA. Role of beta1-Integrin in Colorectal Cancer: Case-Control Study. Ann Coloproctol. 2014; 30:61-70.

11. Saridaki Z, Souglakos J and Georgoulias V. Prognostic and predictive significance of MSI in stages II/III colon cancer. World J Gastroenterol. 2014; 20:6809-6814.

12. Brzozowa M, Michalski M, Wyrobiec G, Piecuch A, Dittfeld A, Harabin-Slowinska M, Boron D and Wojnicz R. The role of Snaill transcription factor in colorectal cancer progression and metastasis. Contemp Oncol (Pozn). 2015; 19:265-270.

13. Qin Y, Tang B, Hu CJ, Xiao YF, Xie R, Yong X, Wu YY, Dong $\mathrm{H}$ and Yang SM. An hTERT/ZEB1 complex directly regulates E-cadherin to promote epithelial-to-mesenchymal transition (EMT) in colorectal cancer. Oncotarget. 2016; 7:351-361. doi: 10.18632/oncotarget.5968.

14. Li C, Wang J, Kong J, Tang J, Wu Y, Xu E, Zhang H and Lai M. GDF15 promotes EMT and metastasis in colorectal cancer. Oncotarget. 2016; 7:860-872. doi: 10.18632/ oncotarget.6205.

15. Alam SK, Yadav VK, Bajaj S, Datta A, Dutta SK, Bhattacharyya M, Bhattacharya S, Debnath S, Roy S, Boardman LA, Smyrk TC, Molina JR, Chakrabarti S, Chowdhury S, Mukhopadhyay D and Roychoudhury 
S. DNA damage-induced ephrin-B2 reverse signaling promotes chemoresistance and drives EMT in colorectal carcinoma harboring mutant p53. Cell Death Differ. 2015.

16. Ziadi S, Ksiaa F, Ben Gacem R, Labaied N, Mokni M and Trimeche M. Clinicopathologic characteristics of colorectal cancer with microsatellite instability. Pathol Res Pract. 2014; 210:98-104.

17. Kim JH, Bae JM, Kim KJ, Rhee YY, Kim Y, Cho NY, Lee HS, Chang MS and Kang GH. Differential Features of Microsatellite-Unstable Colorectal Carcinomas Depending on EPCAM Expression Status. Korean J Pathol. 2014; 48:276-282.

18. Goldstein J, Tran B, Ensor J, Gibbs P, Wong HL, Wong SF, Vilar E, Tie J, Broaddus R, Kopetz S, Desai J and Overman MJ. Multicenter retrospective analysis of metastatic colorectal cancer (CRC) with high-level microsatellite instability (MSI-H). Ann Oncol. 2014; 25:1032-1038.

19. Lin CC, Lai YL, Lin TC, Chen WS, Jiang JK, Yang SH, Wang HS, Lan YT, Liang WY, Hsu HM, Lin JK and Chang SC. Clinicopathologic features and prognostic analysis of MSIhigh colon cancer. Int J Colorectal Dis. 2012; 27:277-286.

20. Cheng GZ, Chan J, Wang Q, Zhang W, Sun CD and Wang LH. Twist transcriptionally up-regulates AKT2 in breast cancer cells leading to increased migration, invasion, and resistance to paclitaxel. Cancer Res. 2007; 67:1979-1987.

21. Li S, Kendall SE, Raices R, Finlay J, Covarrubias M, Liu Z, Lowe G, Lin YH, Teh YH, Leigh V, Dhillon S, Flanagan S, Aboody KS and Glackin CA. TWIST1 associates with NF-kappaB subunit RELA via carboxyl-terminal WR domain to promote cell autonomous invasion through IL8 production. BMC Biol. 2012; 10:73.

22. Stankic M, Pavlovic S, Chin Y, Brogi E, Padua D, Norton L, Massague J and Benezra R. TGF-beta-Id1 signaling opposes Twistl and promotes metastatic colonization via a mesenchymal-to-epithelial transition. Cell Rep. 2013; 5:1228-1242.

23. Way TD, Huang JT, Chou CH, Huang CH, Yang MH and Ho CT. Emodin represses TWIST1-induced epithelialmesenchymal transitions in head and neck squamous cell carcinoma cells by inhibiting the beta-catenin and Akt pathways. Eur J Cancer. 2014; 50:366-378.

24. Watanabe O, Imamura H, Shimizu T, Kinoshita J, Okabe T, Hirano A, Yoshimatsu K, Konno S, Aiba M and Ogawa $\mathrm{K}$. Expression of twist and wnt in human breast cancer. Anticancer Res. 2004; 24:3851-3856.

25. Xue G, Restuccia DF, Lan Q, Hynx D, Dirnhofer S, Hess D, Ruegg C and Hemmings BA. Akt/PKB-mediated phosphorylation of Twist1 promotes tumor metastasis via mediating cross-talk between PI3K/Akt and TGF-beta signaling axes. Cancer Discov. 2012; 2:248-259.

26. Li J and Zhou BP. Activation of beta-catenin and Akt pathways by Twist are critical for the maintenance of EMT associated cancer stem cell-like characters. BMC Cancer. 2011; 11:49.

27. Kurrey NK, Jalgaonkar SP, Joglekar AV, Ghanate AD, Chaskar PD, Doiphode RY and Bapat SA. Snail and slug mediate radioresistance and chemoresistance by antagonizing p53-mediated apoptosis and acquiring a stem-like phenotype in ovarian cancer cells. Stem Cells. 2009; 27:2059-2068.

28. Mani SA, Guo W, Liao MJ, Eaton EN, Ayyanan A, Zhou AY, Brooks M, Reinhard F, Zhang CC, Shipitsin M, Campbell LL, Polyak K, Brisken C, Yang J and Weinberg RA. The epithelial-mesenchymal transition generates cells with properties of stem cells. Cell. 2008; 133:704-715.

29. Morel AP, Lievre M, Thomas C, Hinkal G, Ansieau S and Puisieux A. Generation of breast cancer stem cells through epithelial-mesenchymal transition. PLoS One. 2008; 3:e2888.

30. Creighton CJ, Li X, Landis M, Dixon JM, Neumeister VM, Sjolund A, Rimm DL, Wong H, Rodriguez A, Herschkowitz JI, Fan C, Zhang X, He X, Pavlick A, Gutierrez MC, Renshaw L, Larionov AA, Faratian D, Hilsenbeck SG, Perou CM, Lewis MT, Rosen JM and Chang JC. Residual breast cancers after conventional therapy display mesenchymal as well as tumor-initiating features. Proc Natl Acad Sci U S A. 2009; 106:13820-13825.

31. Al-Hajj M, Wicha MS, Benito-Hernandez A, Morrison SJ and Clarke MF. Prospective identification of tumorigenic breast cancer cells. Proc Natl Acad Sci U S A. 2003; 100:3983-3988.

32. Singh SK, Hawkins C, Clarke ID, Squire JA, Bayani J, Hide T, Henkelman RM, Cusimano MD and Dirks PB. Identification of human brain tumour initiating cells. Nature. 2004; 432:396-401.

33. Li C, Heidt DG, Dalerba P, Burant CF, Zhang L, Adsay V, Wicha M, Clarke MF and Simeone DM. Identification of pancreatic cancer stem cells. Cancer Res. 2007; 67:1030-1037.

34. Li X, Lewis MT, Huang J, Gutierrez C, Osborne CK, Wu MF, Hilsenbeck SG, Pavlick A, Zhang X, Chamness GC, Wong H, Rosen J and Chang JC. Intrinsic resistance of tumorigenic breast cancer cells to chemotherapy. J Natl Cancer Inst. 2008; 100:672-679.

35. Dean M, Fojo T and Bates S. Tumour stem cells and drug resistance. Nat Rev Cancer. 2005; 5:275-284.

36. Sinicrope FA, Foster NR, Thibodeau SN, Marsoni S, Monges G, Labianca R, Kim GP, Yothers G, Allegra C, Moore MJ, Gallinger S and Sargent DJ. DNA mismatch repair status and colon cancer recurrence and survival in clinical trials of 5-fluorouracil-based adjuvant therapy. J Natl Cancer Inst. 2011; 103:863-875.

37. Shelygin YA, Pospekhova NI, Shubin VP, Kashnikov VN, Frolov SA, Sushkov OI, Achkasov SI and Tsukanov AS. Epithelial-mesenchymal transition and somatic alteration in colorectal cancer with and without peritoneal carcinomatosis. Biomed Res Int. 2014; 2014:629496.

38. Roepman P, Schlicker A, Tabernero J, Majewski I, Tian S, Moreno V, Snel MH, Chresta CM, Rosenberg R, Nitsche U, Macarulla T, Capella G, Salazar R, Orphanides G, Wessels LF, Bernards R and Simon IM. Colorectal cancer intrinsic subtypes predict chemotherapy benefit, deficient mismatch repair and epithelial-to-mesenchymal transition. Int J Cancer. 2014; 134:552-562. 
39. Lee KW, Kim JH, Han S, Sung CO, Do IG, Ko YH, Um SH and Kim SH. Twist1 is an independent prognostic factor of esophageal squamous cell carcinoma and associated with its epithelial-mesenchymal transition. Ann Surg Oncol. 2012; 19:326-335.
40. Shen L, Zeng S, Chen J, Zhong M, Yang H, Yao R and Shen H. E1A inhibits the proliferation of human cervical cancer cells (HeLa cells) by apoptosis induction through activation of HER-2/Neu/Caspase-3 pathway. Med Oncol. 2008; 25:222-228. 